\title{
The Changing Faces of America's Children and Youth
}

\author{
KENNETH M. JOHNSON AND DANIEL T. LICHTER
}

$\mathrm{R}$ ecent U.S. Census Bureau projections indicate that by the middle of this century, non-Hispanic whites will cease to be a majority of the American population. For America's youngest residents, the future is already here. Last year, 48.6 percent of the babies born in the United States were members of minority groups. The seeds of diversity are being sown by high rates of childbearing among America’s minorities. Here we document how these demographic forces have placed today's children and youth in the vanguard of America's new racial and ethnic diversity. America's rapidly changing racial and ethnic composition has important implications for inter-group relations, ethnic identities, and electoral politics. ${ }^{1}$

Growing racial diversity is attributable in large part to the unprecedented increases in minority children, especially Hispanic children. Less well appreciated are declines of the population of non-Hispanic white children. These national patterns have played out unevenly over geographic space. By 2008, more than 500 U.S. counties had "majority-minority" populations of children compared to only slightly more than 300 counties in which minorities represented more than 50 percent of the entire population. The frequent claim that we live in an increasingly multiracial or multicultural society-a fact that is both celebrated and feared-does not necessarily mean that national patterns are played out consistently at the local or regional level.

\section{Key Findings}

- Nearly forty-nine percent of births last year were to minorities. Children are in the vanguard of America's increasing racial and ethnic dviersity, and the minority child population is growing.

- The non-Hispanic white child population is declining.

- Growing child diversity is geographically widespread but uneven.

\section{Growing Racial and Ethnic Diversity among America's Children}

Roughly one-third of the U.S. population today belongs to a racial or ethnic minority group. The pace of racial change has been especially rapid among Americass young population. In 1990,32 percent of the population under age 20 was minority. It grew to 39 percent in 2000. By July 2008, 43 percent of the 82.6 million young people in America were from minority populations (see Figure 1). In contrast, minorities represented only 31 percent of the 221.4 million residents age 20 or older. Among this older population, Hispanics (13 percent) comprise a slightly larger share of the population than blacks (11 percent). But Hispanics constitute 21 percent of the under 20 population compared to 14 percent among blacks.

The acceleration of racial and ethnic diversity is underscored when we compare the youngest and oldest cohorts of young people. Minorities represented 47 percent of the population under age 5 in 2008 but only 40 percent among 15 to 19 year olds. The age gradient of minority representation clearly highlights America's new and growing diversity. It also

Figure 1. U.S. POPULATION BY RACE/ETHNiCITY, 2008

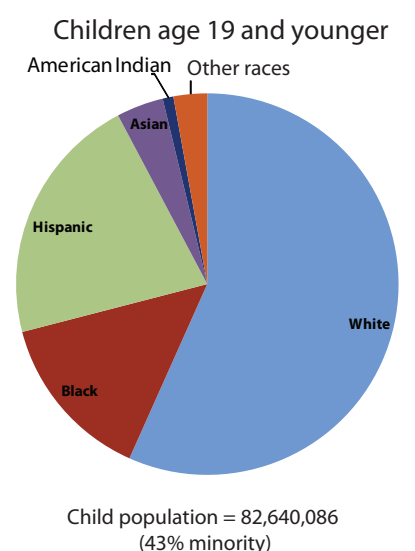

Source: U.S. Census Bureau Population Estimates 2009
Adults age 20 and over

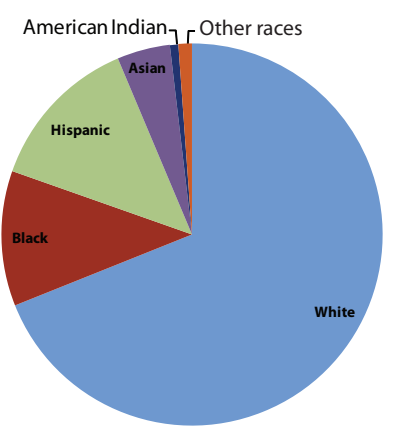

Adult population $=221,419,638$ ( $31 \%$ minority) 
Figure 2. Population Change for those under Age 20 BY RACE/HISPANIC ORIGIN, 1990 TO 2000 AND 2000 TO 2008

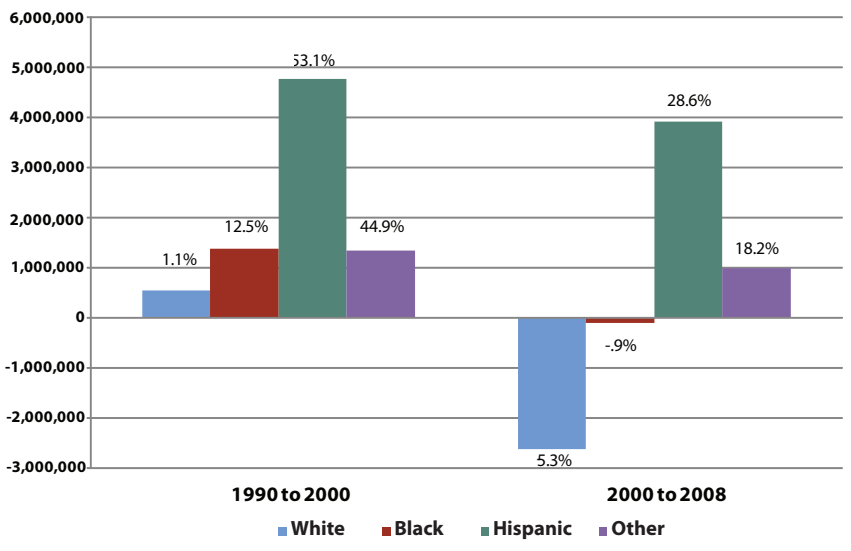

Source: U.S. Census Bureau Population Estimates, 2009; Decennial Census 1990,2000

provides a portent of America's demographic future.

The growth of America's minorities, coupled with recent declines in the white population, has placed young people in the vanguard of America's new diversity. Between 2000 and 2008 , the number of minority children grew by 4.8 million (15.5 percent). Hispanics accounted for 3.9 million, or more than 80 percent of the increase (see Figure 2). The number of young people in other minority groups (primarily Asian) also grew by 985,000 (18.2 percent). In contrast, the population of black young people declined (-.9 percent) over the same period. The decline of young blacks-historically the largest minority group in the country-underscores the fundamental demographic changes underway in America's minority population.

Demographic changes in the white population also have been large. The number of young whites increased by only 54,000 , or roughly 1 percent, during the 1990s. Since 2000, non-Hispanic white children and youth declined absolutely by 2.6 million ( 5.3 percent). As a result, the proportion of the young population that was non-Hispanic white declined from 61 to 57 percent between 2000 and 2008. Most of this change (65 percent) occurred because the number of minority young people grew, but a significant share (35 percent) was due to absolute declines in non-Hispanic whites.

\section{Minority Births Up, White Births Down}

Fertility has played an important role in these shifting patterns of racial change. In 1990, non-Hispanic whites accounted for nearly two-thirds of all births. Blacks accounted for the second largest number of births (17 percent), followed by Hispanics at approximately 15 percent. By 2008,
Figure 3. Change in WOMEN AGE 20 TO 39 BY RACE AND HISPANIC ORIGIN, 1990 TO 2000 AND 2000 TO 2008

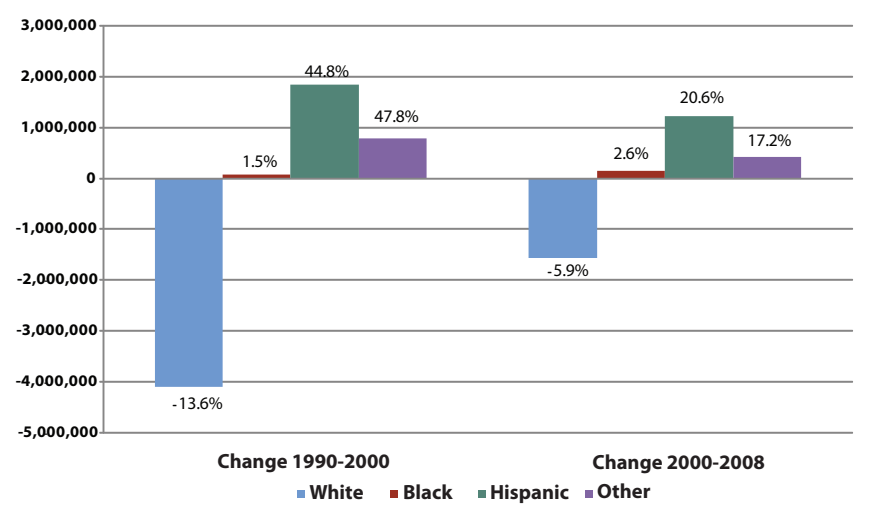

Source: U.S. Census, 1990 and 2000; U.S. Census Bureau Population Estimates, 2009

U.S. births increased by less than 5 percent, but Hispanic births rose 84 percent. Births among non-Hispanic whites and blacks declined absolutely from 2000 to 2008. By 2008, non-Hispanic whites accounted for roughly half of all births, while Hispanics contributed 26 percent, and blacks were about 16 percent.

Declines in the number of white women of childbearing age have also contributed to recent racial change. During the 1990s, the number of non-Hispanic white women of prime childbearing age (20-39) declined by more than four million (-13.6 percent). The number of non-Hispanic white women of prime childbearing age declined by another 1.6 million between 2000 and 2008 (see Figure 3). In contrast, the number of minority women of prime childbearing age grew by 2.7 million (24 percent) and 1.8 million (13 percent) in the 1990s and 2000s, respectively. Hispanic women account for nearly 68 percent of this absolute minority gain. The number of other minority women also grew significantly from 1990 to 2008 , although increases in the number of black women of reproductive age were minimal.

The cumulative impact of changes in the number of women of childbearing age has been considerable. By 2008, there were 5.6 million (19 percent) fewer non-Hispanic white women of prime childbearing age than there were in 1990. In contrast, there were 4.5 million ( 40 percent) more minority women in their prime childbearing years. As a result, the proportion of all women in their prime childbearing years who were non-Hispanic white diminished from 73 percent in 1990 to 61 percent in 2008.

High Hispanic fertility rates and early childbearing are responsible for exceptionally large numbers of Hispanic births over the past decade or so. Indeed, current fertility rates indicate that Hispanic women will have 2.99 children over their reproductive lives. Early childbearing also characterizes the Hispanic population; 44 percent of their 
childbearing occurs by age 25 . In contrast, non-Hispanic white women have 1.87 children. They also tend to have them later with only about 30 percent of their children born by age 25 . African American women also have their children earlier, but recent black fertility declines from 2.5 children per woman in 1990 to 2.13 in 2007 contributed to the reduction in young black people. The groups that compose most of our "other" minority category (Asians and Native Americans) also have relatively low total fertility (2.04 and 1.86 respectively), so recent youth gains in these groups are due to the rising numbers of women of childbearing age (mostly due to Asian immigration) rather than to high fertility rates. Clearly, below-replacement fertility among non-Hispanics exacerbates the demographic impact of the growing number of minority women with high fertility on America's racial and ethnic mix.

\section{Hispanics Fuel Much of Minority Youth Growth}

From a demographic standpoint, Hispanics are driving rapid increases in racial diversity among America's children. In fact, 82 percent of the growth in the minority child population between 2000 and 2008 was due to Hispanic births. The initial impetus for these recent Hispanic child gains was immigration-between 2000 and 2008, 4.3 million Hispanics immigrated to the United States, supplementing the 7.7 million who arrived during the 1990s. Most new immigrants are young adults in their reproductive prime. This influx coupled with the large Hispanic population already in the United States produced the surge in Hispanic births.

The growing importance of births is reflected in the fact that nearly two-thirds of the entire Hispanic population gain in the last year came from natural increase-the difference between births and deaths-rather than immigration. And this proportion is increasing. Last year, there were ten births for every Hispanic death. In contrast, the ratio is 1.38 births for every death among non-Hispanics. The cumulative impact of this high birth-to-death ratio is reflected in the growing number of Hispanic children and in the growing proportion of all U.S. growth attributable to Hispanics. Hispanics accounted for 51.4 percent of the U.S. population gain between 2000 and 2008 .

Perhaps paradoxically, growing shares of minority children are U.S.-born rather than born in other countries. In fact, native-born children accounted for at least 97 percent of all children under age 5 for each of the major minority groups considered here. Of course, a substantial share of native-born minorities was born to foreign-born parents, some of whom are undocumented aliens. This has raised new policy concerns about so-called "anchor babies" - children who are U.S. citizens but whose parents are undocumented. In 2008, only 39 percent of Hispanic children age 4 and younger had two native-born parents. An additional 17 percent had one native-born parent, and the remaining 44 percent had two foreign-born parents. The Pew Center estimates that 40 percent of native-born Hispanics under age 18 with at least one foreign-born parent has at least one unauthorized parent. However, the oldest U.S.-born children of the Hispanic immigrant streams that arrived in large numbers in the 1980s and 1990s now are having children of their own. The proportion of Hispanic children with U.S.-born parents is expected to grow over the foreseeable future. In fact, the Pew Center estimates that the share of Hispanic youth who are the children of immigrants will soon peak. ${ }^{2}$

\section{Minority Youth Populations are Spreading from Traditional Enclaves, but Distribution Remains Uneven}

The conventional wisdom is that growing diversity is largely a big-city phenomenon, but the evidence suggests otherwise. The new growth of minority children is spatially broad based. In fact, the largest absolute and percentage gains are outside the urban core counties of metropolitan areas with more than one million residents (see Figure 4). Indeed, the suburban and smaller metropolitan counties, where minority gains are now most heavily concentrated, are home to 44.6 million (54 percent) of the nation's 82.6 million young people. A significant majority are non-Hispanic white (63 percent) despite a decline of more than one million (-3.7 percent) since 2000. In contrast, each minority population of children and youths grew rapidly here. The number of Hispanics has swelled by 2.1 million (37 percent) since 2000;

Figure 4. Population Change for population Under AGE 20 BY RACE/HiSPANIC ORIGIN, 2000 TO 2008

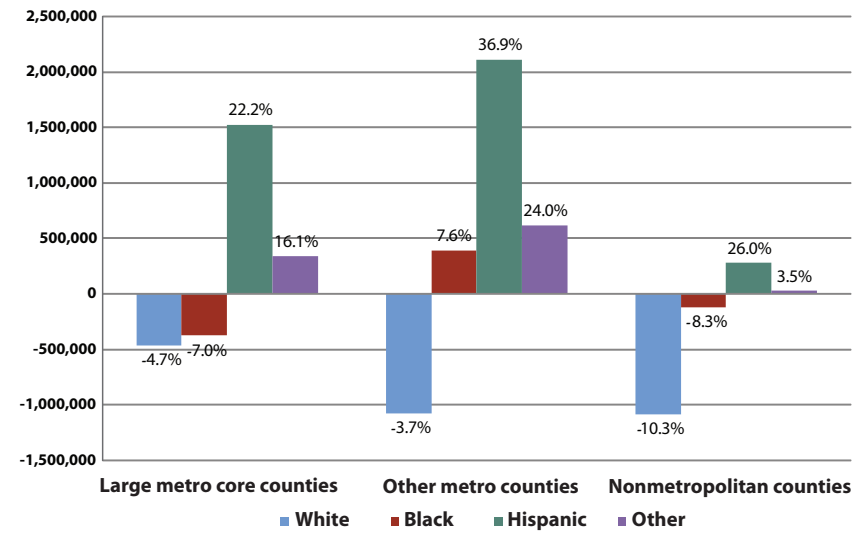

Source: U.S. Census Population Estimates, 2009 
FiguRE 5. DISTRIBUTION OF MINORITY AND NON-HISPANIC WHITE POPULATION UNDER AGE 20, 2008

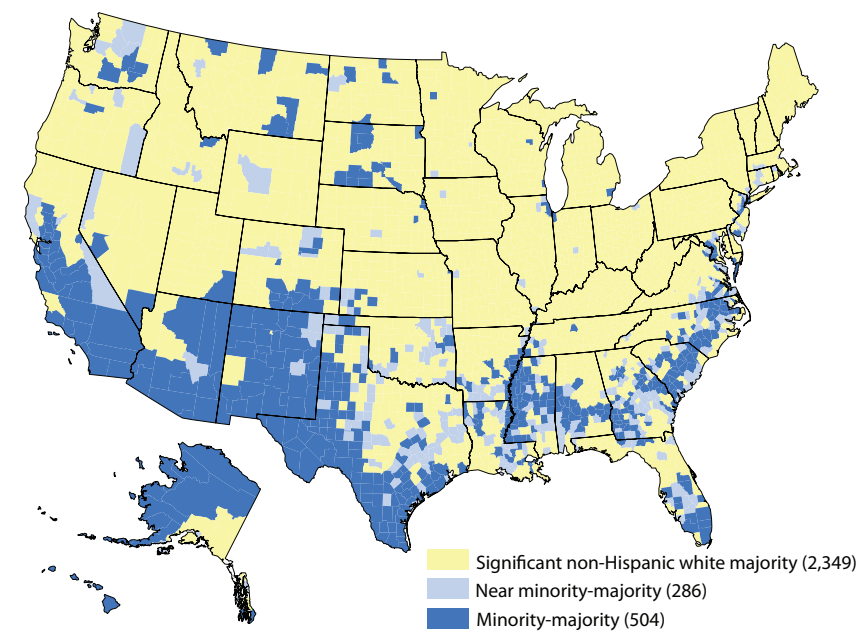

Source: U.S. Census Bureau Population Estimates 2009

this is the largest gain of any minority population in any area during this period.

In the large urban cores, where minority populations have traditionally clustered, 63 percent of the 25.2 million children and youth are minority. The population of minority children has grown by more than one million in these areas since 2000. Declines among blacks and whites have been largely offset by large Hispanic population gains.

Compared with metropolitan areas, minority children constitute a considerably smaller proportion of all nonmetropolitan children ( 26 percent versus 45 percent). Rural areas actually had 900,000 fewer young people in 2008 than 2000 because there were one million ( -10.3 percent) fewer non-Hispanic white youth in 2008 than in 2000 . The population loss among young black people was nearly as large as whites in percentage terms (-8.3 percent). Significant gains in Hispanic young people (26.5 percent) were insufficient to offset overall population losses. As a result, the rural youth population declined by 6.5 percent after 2000 .

National trends may mask geographic variation in America's racial and ethnic makeup. Indeed, 504 counties now have a majority of minority young people (that is, majority-minority counties), and another 286 are "near" majority-minority with between 40 and 50 percent minority youth populations (see Figure 5). These patterns among young people clearly are a harbinger of future racial change and diversity in America, especially as deaths among the older, largely white population are replaced disproportionately by minority births. In 2008, many more counties had majority-minority youth populations than had overall majority-minority populations (504 versus 309).

Not surprisingly, majority-minority counties are concen-
FIGURE 6. RACIAL DIVERSITY OF YOUNG PEOPLE IN U.S. COUNTIES, 2008

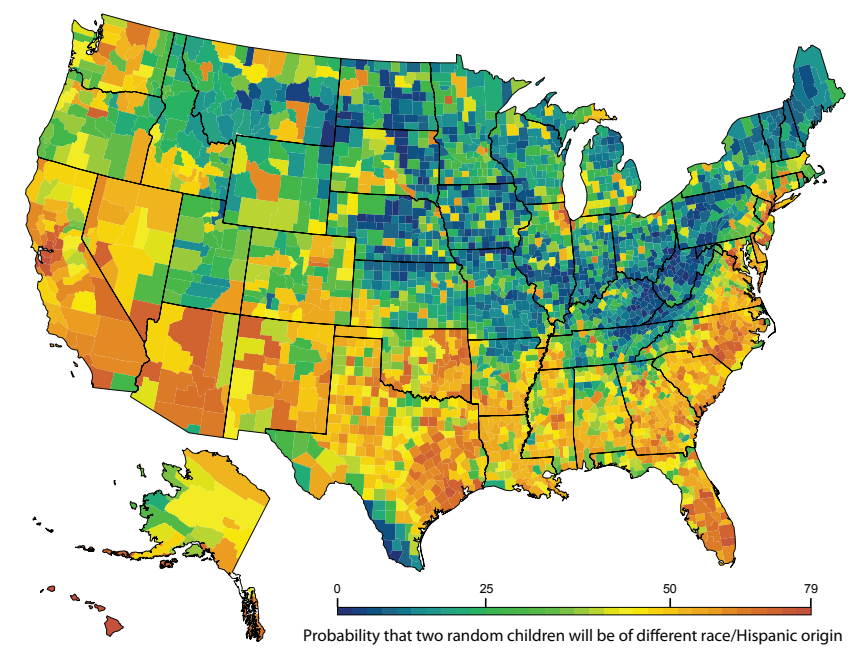

Source: U.S. Census Bureau Population Estimates 2009

trated in traditional minority settlement areas. For example, large minority population clusters, especially in the Southwest and the Mississippi Delta, are a continuing legacy of America's past (for example, slavery in the South). New concentrations of majority-minority counties in the Carolinas and Georgia, in the Pacific Northwest, and in Colorado also reflect the geographic spread of minority children and youth, especially of Hispanics.

Even in regions where minorities are not approaching majority status, there is growing diversity. To illustrate this, we calculate a diversity index, which indicates the probability that two randomly selected young people in a county will be of a different race or ethnicity (Hispanic origin or not). For example, a diversity index of .50 means that a young person residing in that county has roughly a 50 percent chance of random exposure to a young county resident who is different from themselves.

Nearly all of the Southeast and Southwest have at least moderate levels of diversity, and that diversity extends to the large sprawling metropolitan regions of the Midwest and the East (see Figure 6). However, large areas of the country show little if any racial and ethnic diversity. This includes the vast agriculture heartland in the upper Midwest, with the exception of scattered counties in the Great Plains (Native American reservations and new Hispanic destinations with meat packing plants). Diversity is also modest in the Northeast in areas outside the coastal urban agglomeration.

The combination of specific minority groups that create diversity, or limit it, varies from place to place (see Figure 7). Here, a spatial representation of minority youth concentrations reflects the number of minority groups who represent more than 10 percent of the youth population in a 
Figure 7. ETHNIC COMPOSITION OF POPULATION UNDER AGE 20 FOR U.S. COUNTIES, 2008

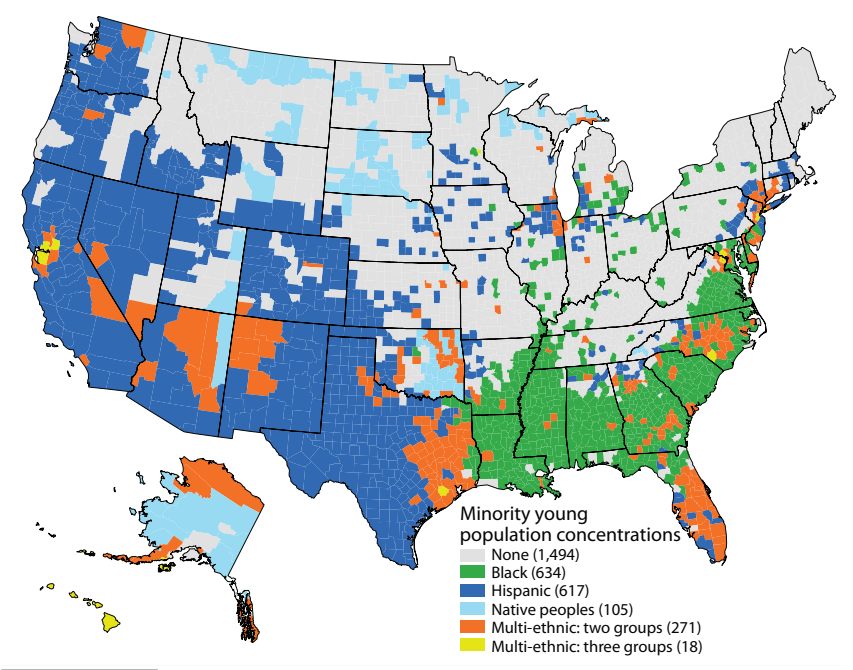

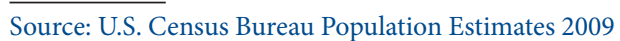

given county. The map reflects both the vestiges of historical minority settlement patterns and the influence of contemporary demographic trends. The large county clusters with significant black youth minorities in the South reflects historical black settlement patterns in the old plantation South. The spatial dispersion of Hispanics in the Southwest reflects both historical patterns of border settlement and contemporary migration and natural increase. The broadly scattered clusters of native peoples also reflect a legacy of traditional settlement patterns and forced resettlement. However, for nearly one-half of all counties, no minority groups are represented at even a 10 percent level. This underscores a simple but straightforward demographic point: national data is often used to suggest the rapid spread of multiculturalism, but this glosses over large disparities in the spatial distribution of minority youth.

Indeed, fewer than 300 counties are comprised of even two minority groups. It is nevertheless in these counties where the impact of contemporary trends is most evident. In North Carolina where blacks were once the only visible minority population, diversity is now being redefined by the recent arrival of Hispanics. ${ }^{3}$ The scattered Hispanics clusters in traditional agricultural areas of the Great Plains and Corn Belt also reflect contemporary demographic trends. Here the demand for labor in agricultural-related industries, such as meat packing and irrigated agriculture, exceeds the local labor force depleted by decades of out-migration and low fertility. The influx of these young Hispanic families has important demographic consequences as well. Minority inmigration may break the cycle of natural decrease caused by persistent out-migration and low fertility.
In the Washington, D.C., metropolitan area, the historical concentration of blacks, combined with recent in-migration of Hispanics and Asians, have produced one of America's most diverse populations of children and youth. Such broadly diverse counties remain rare, however, even when our demographic lens is focused on young people. Only 18 of the 3,141 U.S. counties contain three or more identifiable minority youth populations.

\section{Discussion and Conclusion}

With the election of Barak Obama as president of the United States, issues of race and racial inclusion have moved to the forefront of public discourse in America. The influx of roughly one million immigrants annually-mostly from Latin America and Asia-has further fueled debates about multiculturalism and social, economic, and cultural fragmentation (for example, English language usage, rising intermarriage, growing mixed-race populations, and political and economic power). The U.S. Census Bureau's recent projection of a majority-minority U.S. population by the middle of the century has sometimes been the source of alarmist rhetoric about America's future and its essential character. We argue here that the seeds of racial and ethnic multiculturalism are also being sown by recent fertility patterns, which is revealed in the rapidly growing racial and ethnic diversity among America's children and youth.

Our research highlights the two demographic forces that have placed today's young people in the vanguard of America's new racial and ethnic diversity. The first is the rapid increase in the number of minority youths, with Hispanics accounting for the vast majority of the gain since 2000. A second but less widely recognized shift is the absolute decline of non-Hispanic white young people. Together these two trends have significantly increased the proportion of all American youth who are minority. America is well on the way to becoming a majority-minority society with youth leading the way.

Our results also highlighted the growing racial divide along the dimensions of age and geography. Some 48.6 percent of the babies born last year were minority compared to 35 percent of the 40 to 45 year olds and less than 20 percent of those 65 and older. This raises important questions about intergenerational support for social programs. ${ }^{4}$ For example, will America's older, largely white population-through the ballot box and collective self-interest-support young people who are now much different culturally from themselves and their own children? Will they vote, for example, to raise taxes for schools that serve young people who do not look like they do? Some evidence suggests that the presence of large fractions of elderly residents in a jurisdiction was associated with significantly less per-child educational spending, especially if the elderly and children were of different races. ${ }^{5}$ On the other hand, it is also likely that an increasing share of 
America's seniors will have children and grandchildren who are in or are the products of interracial marriages, a fact that binds generations rather than separates them.

Our finding of greater diversity among the nation's youngest residents also offers some grounds for optimism. Race relations and cultural boundaries, both now and in the future, will be influenced by whether children are growing up in multiracial and multiethnic communities where opportunities for mutual understanding and acceptance are greater or instead living in isolation from each other. For America's young people, growing exposure to racial diversity will remake patterns of interracial relations and friendship networks. Attitude surveys show that young people are much more racially tolerant than older people and that anti-black prejudice has declined with cohort replacement. ${ }^{6}$ Optimism about improved relations among young people of diverse backgrounds must be tempered by spatial disparities in racial composition and diversity. On the one hand, the increasing racial and ethnic diversity of America's youth is no longer limited to the large multiracial urban cores or to regions where minorities historically settled. Instead, the post-2000 period ushered in a new pattern of accelerated spatial dispersion among minority children and youth. Yet, there are broad geographic regions that still provide few opportunities for daily interaction between young people with different racial and cultural backgrounds. Furthermore, our findings of increasing youth racial diversity at the county level do not necessary demonstrate that such diverse communities exist at the town or neighborhood level. ${ }^{7}$ The geographic landscape of race suggests the emergence of two Americas - an increasingly racially diverse one and a largely white one. Opportunities for racial and ethnic interaction vary from place to place as do opportunities for mutual understanding and acceptance.

Our research contributes to policy discussions by highlighting America's new youth diversity and the changing geographic scale of its expression. As we demonstrate here, the changing racial and ethnic composition of America's youngest populations can be traced to two forces: differential changes in the numbers of women of childbearing age by race and Hispanic origin and differential rates of fertility, especially high fertility among Hispanics, which is a by-product of recent immigration trends. In a policy environment usually fixated on immigration, recognizing the rising importance of other demographic factors is no small achievement. With or without restrictive immigration legislation, America is becoming an increasingly diverse society although this diversity is experienced unevenly spatially. Natural increase-especially fertility - will continue to reshape the racial and ethnic mix of the country, and this change will be reflected first among the nation's youngest residents.

\section{Data and Methods}

We use two sources of data for our analyses. First, the primary source of contemporary data is the U.S. Census Bureau's annual estimates of the population by age, sex, race, and Hispanic origin from April 2000 to July 2008, released in May 2009. ${ }^{8}$ Second, we use data from the 1990 and 2000 decennial census that has been adjusted for under-enumeration by age, race, and Hispanic origin and where respondents who classified themselves as multiracial in 2000 were allocated to racial categories to make them compatible with the 1990 census data. ${ }^{9}$

Understanding America's changing racial and ethnic composition is a challenging endeavor in part because measurement is typically based on self-identification or self-reports. Racial and ethnic self-identification is also highly subjective, situational, and fluid. We cannot adjudicate current debates about proper racial and ethnic classification using the secondary data at our disposal. We therefore advise a cautious approach to the evidence and recognition of the inherent subjective nature of our demographic exercise.

For most purposes, we classified the population into four groups: (1) Hispanics of any race; (2) non-Hispanic whites; (3) non-Hispanic blacks; and (4) all other non-Hispanics, including those who reported two or more races. Asians were the largest racial group included in the other category. They constituted 51 percent of the age 19 and under group in the "other" category. We also split the population into two age groups. Persons age 19 or younger were classified as "young," or the youth population. Individuals over age 19 were grouped together into an "adult" category, which we occasionally refer to as the older population.

To examine the uneven spatial distribution of different racial and ethnic populations, we calculated summary measures of diversity. First, we estimated the number and percentage of majority-minority counties - those having at least half their young people from minority groups-and near majority-minority counties - those having between 40 and 50 percent minority populations. Counties were also classified as having minority youth concentrations if more than 10 percent of the young population was from a specific minority group. Black, Hispanic, Asian, and Native American peoples were the four minority groups that reached the 10 percent threshold in at least one county. Counties that had two or more minority groups reaching the 10 percent threshold were classified as multiethnic. We also calculated a diversity index $(D I)$, which measures the racial and ethnic diversity of the population. ${ }^{10}$ It is calculated as $D I=1-\left(\mathrm{H}^{2}+\right.$ $\mathrm{W}^{2}+\mathrm{B}^{2}+\mathrm{A}^{2}+\mathrm{N}^{2}+\mathrm{M}^{2}$ ). $H$ is the proportion Hispanic, $W$ is the proportion non-Hispanic white, $B$ is the proportion nonHispanic Black, $A$ is the proportion non-Hispanic Asian, $N$ is the proportion non-Hispanic Native American, and $M$ is the proportion non-Hispanic multiracial (that is, those with two or more races). The values of DI range from zero, which 
indicates that a county is made up entirely of one race/ethnicity, to a maximum value of .83 , which means that each race/ethnicity constitutes exactly one-sixth of the population. DI has a straightforward and intuitive interpretation. It measures the probability that any two children, picked at random in a county, would be of a different race or ethnicity (Hispanic or not).

Our analysis includes all 3,141 U.S. counties. County equivalents are used in the New England states. Counties are classified as metro or non-metro using the 2003 definition of the Office of Management and Budget. Metro areas include counties containing an urban core of 50,000 or more in population (or central city), along with adjacent counties that are highly integrated with the core county as measured by commuting patterns. There are 1,090 metro counties. The remaining 2,051 counties are classified as non-metro. For ease of exposition, we use the terms metro and urban (and non-metro and rural) interchangeably. We have further identified large metro core counties as those that contain the central city of metropolitan areas of one million or more and consider them separately from all other metropolitan counties. This is an important distinction. Metro counties with large urban cores historically have had large concentrations of minorities.

\section{Endnotes}

1. Anthony Daniel Perez and Charles Hirschman, "The Changing Racial and Ethnic Composition of the U.S. Population: Emerging American Identities," Population and Development Review 35(2009): 1-51; Robert D. Putnam, "E Pluribus Unum: Diversity and Community in the TwentyFirst Century," Scandinavian Political Studies 30(2007): 137-174.

2. Richard Fry and Jeffrey S. Passel, "Latino Children: A Majority Are US-Born Offspring of Immigrants?” (Washington, D.C., Pew Hispanic Center, 2009).

3. John D. Kasarda and James H. Johnson Jr., The Economic Impact of the Hispanic Population on the State of North Carolina (Chapel Hill: Frank Hawkins Kenan Institute of Private Enterprise, University of North Carolina at Chapel Hill, 2006).

4. Samuel H. Preston, "Children and the Elderly: Divergent Paths for America's Dependents," Demography 21(1984): 435-457.

5. James Poterba, "Demographic Structure and the Political Economy of Public Education," Journal of Policy Analysis and Management 16 (1997): 48-66.

6. Glenn Firebaugh and Kenneth E. Davis, "Trends in Anti-Black Prejudice, 1972-1984: Region and Cohort Effects," American Journal of Sociology 94 (1988): 151-172; Kara Joyner and Grace Kao, "School Racial Composition and Adolescent Racial Homophily," Social Science Quarterly 81(2000): 810-826; Daniel T. Lichter and Warren Brown, "Race, Immigration, and the Future of Marriage," in Marriage and Families: Complexities and Perspectives, edited by H. E. Peters and C. M. K. Dush (New York: Columbia University Press, 2009); Robert D. Putnam, "E Pluribus Unum: Diversity and Community in the Twenty-First Century," in Howard Schuman et al., Racial Attitudes in America: Trends and Interpretations, rev. ed. (Cambridge, MA: Harvard University Press, 1997).

7. It is unclear whether diversity and residential integration are increasing within counties (that is, across neighborhoods or cities and suburbs). Indeed, it may be that the growth of minorities in some counties is occurring in tandem with a new kind of racial balkanization at the sub-county level. See the forthcoming Daniel T. Lichter, et al., "Residential Segregation in New Hispanic Destinations: Cities, Suburbs, and Rural Communities Compared," Social Science Research 38(2010).

8. "Annual County Resident Population Estimates by Age, Sex, Race, and Hispanic Origin: April 1, 2000 to July 1, 2008," http://www.census.gov/popest/counties/asrh/files/ CC-EST2008-ALLDATA, retrieved May 29, 2009.

9. Paul R. Voss, et al., "County-Specific Net Migration by Five-Year Age Groups, Hispanic Origin, Race, and Sex, 1990-2000" (Madison: Center for Demographic and Ecology Working Paper. University of Wisconsin-Madison, 2004), CDE 2004-24; Paul R. Voss, et at., "County-Specific Net Migration by Five-Year Age Groups, Hispanic Origin, Race, and Sex, 1990-2000: [United States]," http:/dx.doi.org/10-3886/ ICPSR04171), retrieved May 29, 2009; Kenneth M. Johnson, et al. "Temporal and Spatial Variation in Age-Specific Net Migration in the United States," Demography, 42(4)(2005): 791-812.

10. Philip Meyer and Shawn McIntosh, "The USA Today Index of Ethnic Diversity," International Journal of Public Opinion Research 4(1992): 51-58. 


\section{About the Authors}

Kenneth M. Johnson is senior demographer at the Carsey Institute and professor of sociology at the University of New Hampshire (ken.johnson@unh.edu).

Daniel T. Lichter is director of the Bronenbrenner Life Course Center and Ferris Family professor in the Department of Policy Analysis and Management and in the Department of Sociology at Cornell University.

\section{ACKNOWLEDGMENTS}

This report is based on the authors' recent article "Growing Diversity among America's Children and Youth: Spatial and Temporal Dimensions," which appeared in Population and Development Review 34(2)(2010):327-346. Allison Churilla of the Carsey Institute contributed to the data analysis, and Barb Cook of the Carsey Institute and David Goldblatt of Loyola University-Chicago produced the maps. The helpful comments of Sharon Sassler, the editorial skills of Terri Rippett, and several anonymous reviewers also are gratefully appreciated.

\section{AN Of NERSITY HAMPSHIRE}

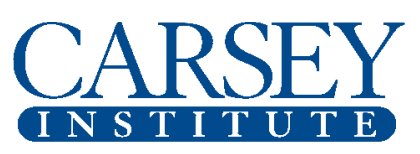

Building knowledge for families and communities

The Carsey Institute conducts policy research on vulnerable children, youth, and families and on sustainable community development. We give policy makers and practitioners timely, independent resources to effect change in their communities.

This research was funded by grants to the Carsey Institute from the Annie E. Casey Foundation, the W.K. Kellogg Foundation, and the Ford Foundation.

Huddleston Hall

73 Main Street

Durham, NH 03824

(603) $862-2821$

www.carseyinstitute.unh.edu 